\title{
Высокоэффективные (EQE $=37.5 \%)$ инфракрасные (850 нм) светодиоды с брэгговским и зеркальным отражателями
}

\author{
(C) А.В. Малевская, Н.А. Калюжный, С.А. Минтаиров, Р.А. Салий, Д.А. Малевский, \\ М.В. Нахимович, В.Р. Ларионов, П.В. Покровский, М.З. Шварц, В.М. Андреев
}

Физико-технический институт им. А.Ф. Иоффре Российской академии наук, 194021 Санкт-Петербург, Россия

E-mail: amalevskaya@mail.ioffe.ru

Поступила в Редакцию 8 июля 2021 r.

В окончательной редакции 2 августа 2021 г.

Принята к публикации 2 августа 2021 г.

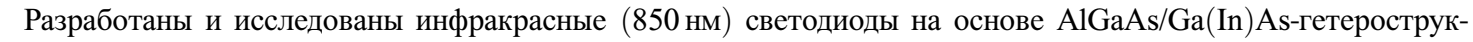
тур, полученных методом МOC-гидридной эпитаксии, включающие множественные InGaAs квантовые ямы в активной области, и двойной оптический отражатель, включающий брэгговскую многослойную $\mathrm{Al}_{0.9} \mathrm{Ga}_{0.1} \mathrm{As} / \mathrm{Al}_{0.1} \mathrm{Ga}_{0.9} \mathrm{As}$-гетероструктуру и зеркальный слой серебра. Изготовлены светодиоды с внешней квантовой эффективностью $\mathrm{EQE}=37.5 \%$ при плотности тока $>10 \mathrm{~A} / \mathrm{cm}^{2}$.

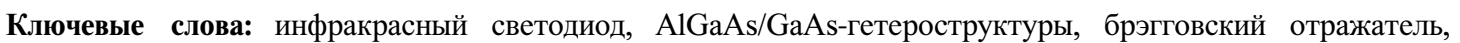
квантовые ямы InGaAs.

DOI: 10.21883/FTP.2021.12.51709.9711

\section{1. Введение}

Уменьшение внутренних оптических потерь в $\mathrm{AlGaAs/GaAs-светодиодах} \mathrm{достигается} \mathrm{либо} \mathrm{удалением}$ ростовой подложки GaAs после выращивания структуры [1-5], либо путем выращивания брэгговского отражателя (БО) на основе многослойной $\mathrm{Al}_{0.9} \mathrm{Ga}_{0.1} \mathrm{As} /$ $\mathrm{Al}_{0.1} \mathrm{Ga}_{0.9} \mathrm{As}$-гетероструктуры между подложкой и активной областью светодиода $[6,7]$.

Брэгговские отражатели характеризуются высоким (порядка 90\%) коэффициентом отражения только для лучей в небольшом телесном угле порядка \pm 20 угл. градусов [8]. По этой причине максимальные значения внешней квантовой эффективности, полученные в $\mathrm{AlGaAs} / \mathrm{GaAs-cветодиодах} \mathrm{на} \mathrm{основе} \mathrm{гетерострук-}$ тур с БО, составляют не более $10 \%$ [6,7].

Высокоэффективные ИК светодиоды на основе MOC-гидридных $\mathrm{AlGaAs/GaAs-гетероструктур} \mathrm{изготав-}$ ливаются $[4,9]$ методом „переноса“ выращенной гетероструктуры на пластину-носитель с нанесенным на поверхность гетероструктуры зеркальным слоем серебра, выполняющим функцию отражателя, с последующим селективным стравливанием ростовой подложки GaAs. Коэффициент внутреннего отражения генерируемого изотропного излучения $(\lambda=850 \mathrm{Hм})$ составляет в таких структурах с Ag-отражателем величину 90\% практически для всех лучей, падающих на поверхность $\mathrm{Ag-отражателя} \mathrm{под} \mathrm{разными} \mathrm{углами,} \mathrm{что} \mathrm{обеспечивает}$ значительно большую величину внешнего квантового выхода в $\mathrm{AlGaAs} / \mathrm{GaAs}$ ИК светодиодах с ,тыльным“ Ag-отражателем $[4,9]$.

В настоящей работе представлены результаты разработок светодиодов $(\lambda=850 \mathrm{Hм})$ с двойным (селективным брэгговским и широкополосным зеркальным) отражателем.

\section{2. Светоизлучающая гетероструктура AIGaAs/Ga(In)As}

Светодиоды изготавливались на основе

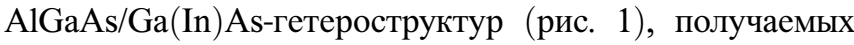
MOC-гидридной эпитаксией на подложках $n$-GaAs, удаляемых в процессе постростовой технологии изготовления светодиодов. Активная область светодиодов включает шесть квантовых ям GaInAs толщиной 3 нм каждая, заключенных между широкозонными $n^{-}$и p-ограничивающими слоями $\mathrm{Al}_{x} \mathrm{Ga}_{1-x} \mathrm{As}(x=0.2-0.4)$. Использование квантовых ям позволяет увеличить концентрацию носителей в тонком слое и получить усиление электронно-дырочного перекрытия, что приводит к увеличению скорости излучательной рекомбинации и, соответственно, к увеличению внутреннего квантового выхода. При этом использование множественных квантовых ям позволяет сохранять основной энергетический уровень квантовой ямы в качестве доминирующего канала рекомбинации даже при высоких уровнях накачки [9].

Для увеличения эффективности вывода света из кристалла между активной областью и тыльной поверхностью структуры выращивался брэгговский отражатель. В отличие от лазерных структур, требующих настройку БО на определенную длину волны, для светодиодов лучше использовать БО, обеспечивающие относительно протяженный спектральный диапазон отражаемого света (40-80 нм).

\section{3. Оптические характеристики брегговского отражателя}

В данной работе БО формировался из $\mathrm{AlGaAs-слоев}$ с максимально различными значениями показателя пре- 


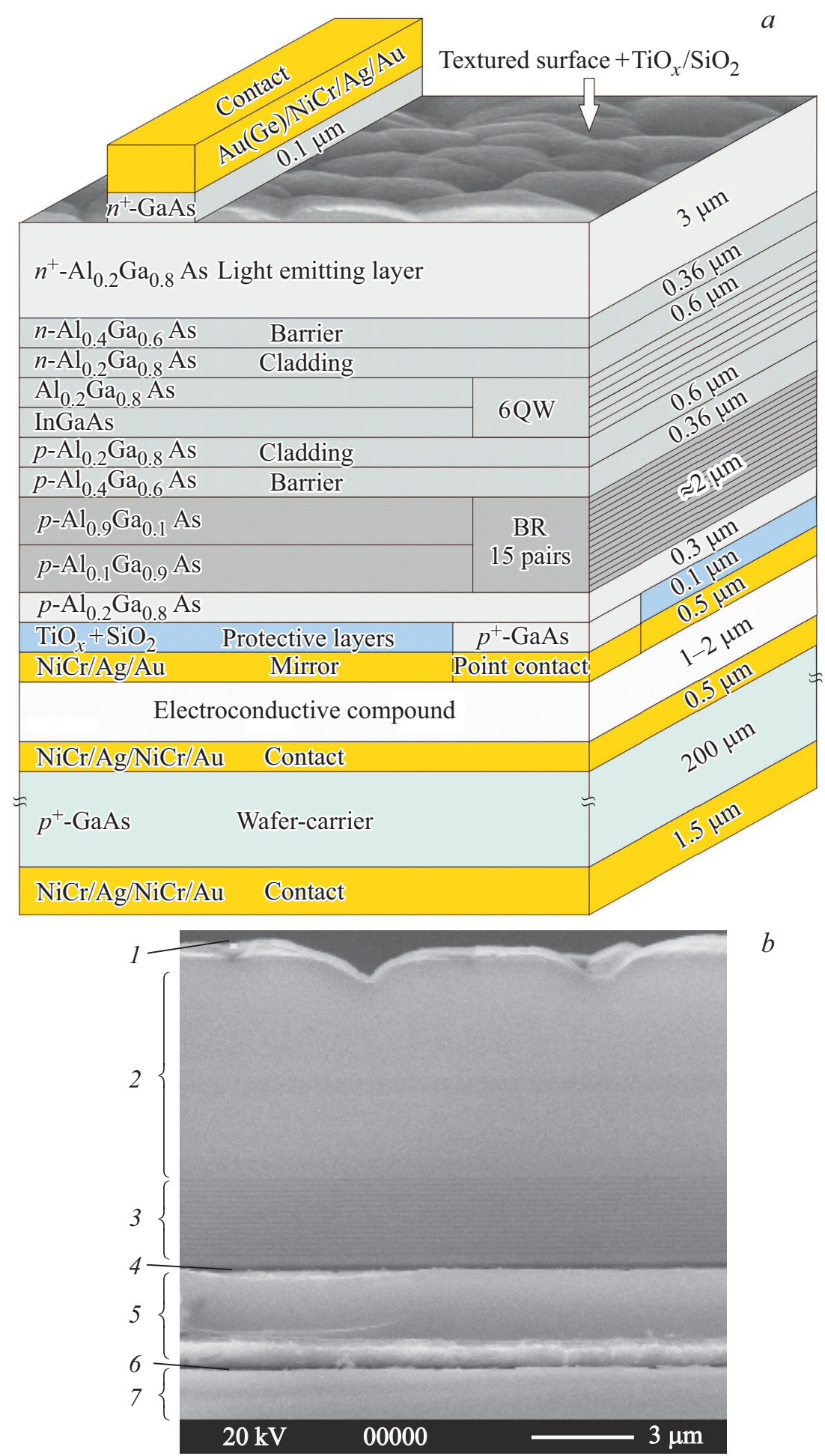

Рис. 1. Схема $(a)$ и изображение скола $(b)$, полученное на растровом электронном микроскопе, светодиода после переноса гетероструктуры на пластину-носитель ( $\left.p^{+} \mathrm{GaAs}\right)$, удаления ростовой подложки $n$-GaAs, текстурирования световыводящей поверхности, нанесения антиотражающего покрытия и омических контактов. 1 - текстурированная поверхность, $2-$ слои гетероструктуры, 3 - БО, 4 - зеркальный отражатель, 5 - серебросодержащий компаунд, 6 - контакт к подложке $p$-GaAs, 7 - подложка $p$-GaAs.

ломления: контраст меньшему показателю преломления $(n)$ широкозонного $\mathrm{Al}_{0.9} \mathrm{Ga}_{0.1} \mathrm{As}$ составлял узкозонный $\mathrm{Al}_{0.1} \mathrm{Ga}_{0.9} \mathrm{As}$ с большим значением показателя пре- ломления. Использование $\mathrm{Al}_{0.1} \mathrm{Ga}_{0.9} \mathrm{As}$ вместо GaAs позволило минимизировать поглощение излучения (850 нм) в БО. Увеличение коэффициента отражения можно полу- 


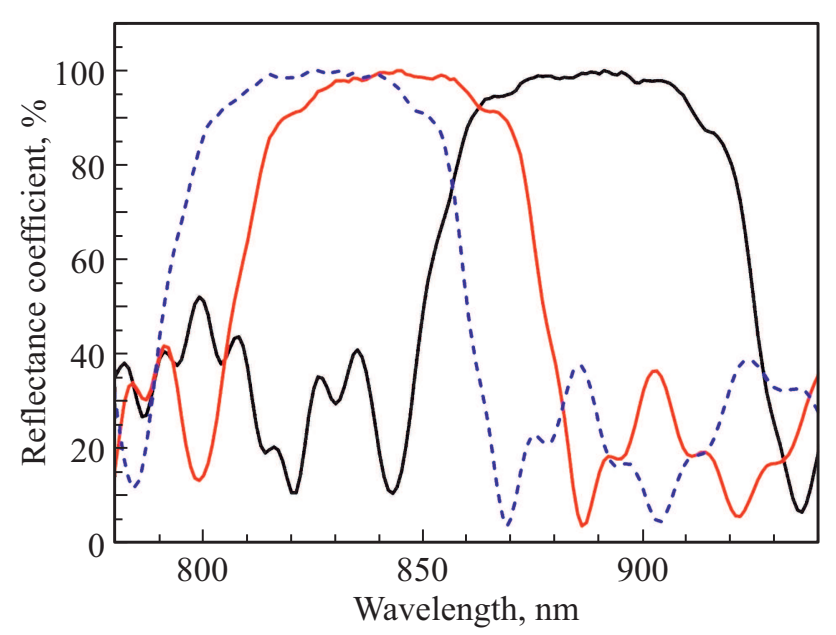

Рис. 2. Спектры отражения структур с брэгговскими отражателями, включающими 15 пар слоев $\mathrm{Al}_{0.9} \mathrm{Ga}_{0.1} \mathrm{As}-\mathrm{Al}_{0.1} \mathrm{Ga}_{0.9} \mathrm{As}$ с различными толщинами.

чить не только за счет увеличения разницы показателей преломления слоев, но и за счет увеличения числа периодов. В разработанной структуре светодиода БО состоял из 15 пар слоев $p-\mathrm{Al}_{0.9} \mathrm{Ga}_{0.1} \mathrm{As} / p-\mathrm{Al}_{0.1} \mathrm{Ga}_{0.9} \mathrm{As}$.

На рис. 2 представлены спектры отражения трех гетероструктур БО, с максимумом отражения, варьируемым в диапазоне $\lambda=800-920$ нм для лучей, падающих на поверхность брэгговских отражателей перпендикулярно плоскостям эпитаксиальных слоев структуры и под углами порядка \pm 20 угл. градусов относительно нормали [8]. Эффективное отражение генерированного в активной области светодиода излучения $(\lambda=850$ нм $)$ и падающего на БО под большими углами может быть получено при увеличении толщины слоев БО. При этом появляется смещение максимумов БО отражения в длинноволновую область спектра для лучей, падающих на БО под углами падения, близкими к прямым. Расширение спектра отражения и, соответственно, углов отражения может быть достигнуто в структурах с двухсекционными БО. Однако было установлено, что увеличение количества и суммарной толщины слоев в БО приводит к увеличению омических потерь [10]. Многочисленные потенциальные барьеры, образуемые слоями с разной шириной запрещенной зоны, препятствуют прохождению носителей заряда в структурах БО и приводят к увеличению последовательного сопротивления, особенно при использовании слоев p-типа [11]. Проблема эффективного транспорта дырок в слоях БО $p$-типа, вследствие их большой эффективной массы [12], действительно существует, а сопутствующее этому возросшее последовательное сопротивление вызывает термический нагрев и, как следствие, ухудшает работу прибора.

Экспериментальные образцы светодиодов изготавливались на основе структур с односекционными брэгговскими отражателями с максимумом отражения в диапазоне длин волн 830-870 нм и дополнялись зер- кальным Ag-отражателем, встраиваемым в светодиод в процессе постростовой обработки и увеличивающим эффективность вывода лучей из кристалла.

В разработанной гетероструктуре светодиода имеет место дополнительное отражение лучей от БО за счет эффекта полного внутреннего отражения от массива слоев $\mathrm{Al}_{0.9} \mathrm{Ga}_{0.1} \mathrm{As} / \mathrm{Al}_{0.1} \mathrm{Ga}_{0.9} \mathrm{As}$ БО, характеризующегося „средним“ содержанием AlAs, равным 50\%, и эффективным показателем преломления $n \simeq 3.3$. Содержание AlAs в среде $\mathrm{Al}_{x} \mathrm{Ga}_{1-x} \mathrm{As}$, из которой излучение падает на БО, аппроксимировано в данной гетероструктуре значением $x=20 \%$, т. е. содержание AlAs в этой среде принято равным содержанию AlAs во фронтальном световыводящем слое структуры. Расчетным путем с использованием результатов работы [7] было установлено, что угол полного внутреннего отражения „латеральных“ лучей от границы $\mathrm{Al}_{0.2} \mathrm{Ga}_{0.8} \mathrm{As} / \mathrm{Al}_{0.5} \mathrm{Ga}_{0.5} \mathrm{As}$ составляет $\sim 20$ угл. градусов. При этом доля генерированного изотропного излучения, претерпевающая полное внутреннее отражение от этой гетерограницы, составляет $35 \%$.

\section{4. Постростовая технология}

Технология изготовления светодиодов на основе выращенных гетероструктур (рис. 1) включала следующие операции:

- создание точечных контактов диаметром 10 мкм с шагом 75 мкм к поверхностному слою $p^{+} \mathrm{GaAs}$;

- удаление контактного слоя $p^{+} \mathrm{GaAs}$ в местах, свободных от точечных контактов для формирования прозрачных окон для генерируемого излучения;

- нанесение диэлектрического покрытия (например, $\left.\mathrm{TiO}_{x} / \mathrm{SiO}_{2}, \mathrm{Si}_{3} \mathrm{~N}_{4}\right)$ в местах, свободных от контактов для защиты и избежания деградации оптических свойств тыльного зеркала;

- нанесение слоя Ag с тонким (1-2 нм) адгезионным слоем $\mathrm{NiCr}$, выполняющего функцию тыльного зеркала с последующим напылением „защитного“ слоя золота;

- переворот и фиксация структуры с помощью серебросодержащего компаунда на пластине-носителе $p^{+} \mathrm{GaAs}$ с предварительно осажденными контактными слоями на фронтальной и тыльной поверхностях;

- селективное стравливание ростовой подложки $n$-GaAs;

- стравливание слоя $n^{+} \mathrm{GaAs}$ в местах, свободных от контактов для открытия световыводящей поверхности;

- текстурирование световыводящей поверхности;

- формирование просветляющего покрытия на основе слоев $\mathrm{TiOx} / \mathrm{SiO}_{2}$ или $\mathrm{Si}_{3} \mathrm{~N}_{4}$;

- создание полосковых контактов к слою $n^{+} \mathrm{GaAs}$;

- монтаж изготовленных чипов светодиодов на теплоотводящую печатную плату и монтаж силиконовой полусферы.

Текстурирование световыводящей поверхности, обеспечивающее увеличение эффективности вывода излучения из светодиодов, выполнялось методом жидкостного 


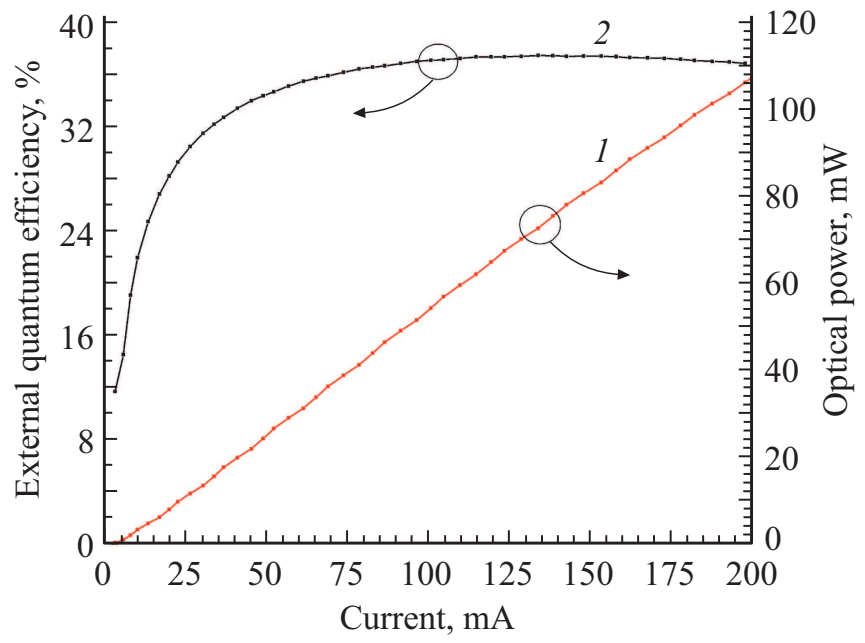

Рис. 3. Ватт-амперная характеристика (1) и токовая зависимость внешней квантовой эффективности (2) светодиода с двойным (БО + серебряное зеркало) отражателем.

химического травления в составе на основе плавиковой кислоты, фтористого аммония и перекиси водорода с образованием полусфер высотой 0.2-0.5 мкм, что обеспечило максимальное увеличение интенсивности электролюминесценции и эффективности светодиода. Осаждение диэлектрического просветляющего покрытия на текстурированную поверхность выполняет защитную функцию и обеспечивает снижение френелевского отражения излучения, выходящего из кристалла.

\section{5. Характеристики светодиодов}

Для анализа электролюминесцентных характеристик светодиодов были проведены исследования ваттамперных характеристик и внешней квантовой эффективности светодиодов, полученных с использованием разработанных ростовой и постростовой технологий. Измерения выполнены в диапазоне токов 0-200 мА, пропускаемых через исследуемые образцы в импульсном режиме.

На рис. 3 представлены токовые зависимости выходной оптической мощности (кривая 1) и внешней квантовой эффективности (EQE, кривая 2) светодиода площадью $1 \mathrm{Mм}^{2}$. Максимальное полученное значение внешней квантовой эффективности светодиода составило $\mathrm{EQE}=37.5 \%$ в диапазоне токов $100-200 \mathrm{MA}$.

\section{6. Заключение}

Методом МОС-гидридной эпитаксии изготовлены $\mathrm{AlGaAs} / \mathrm{Ga}(\mathrm{In}) \mathrm{As}$-гетероструктуры для светодиодов $(\lambda=850$ нм $)$ с двойным (БО + серебряное зеркало) отражателем. Показано, что структура брэгговского отражателя обеспечивает как зеркальное отражение для лучей, приходящих к БО под углами, близкими к нормали, так и полное внутреннее отражение для „латеральных“ лучей, падающих на БО под углами $\sim 20$ угл.градусов к плоскости слоев гетероструктуры. Разработана постростовая технология изготовления светодиодов, включающая перенос структуры с зеркальным (Ag) слоем на пластину-носитель $p^{+} \mathrm{GaAs}$ с последующим стравливанием ростовой $n$-GaAs подложки, текстурированием световыводящей поверхности и нанесением просветляющего покрытия и омических контактов.

В изготовленных светодиодах зарегистрировано значение внешней квантовой эффективности $\mathrm{EQE}=37.5 \%$, заметно превосходящее результаты для приборов на основе подобных гетероструктур, включающих либо брэгговский [7], либо зеркальный (серебряный) [9] отражатели.

\section{Конфликт интересов}

Авторы заявляют, что у них нет конфликта интересов.

\section{Список литературы}

[1] Ж.И. Алфёров, В.М. Андреев, Д.3. Гарбузов, Н.Ю. Давидюк, Б.В. Егоров, Б.В. Пушный, Л.Т. Чичуа. ФТП, 48 (4), 809 (1978).

[2] А.Л. Закгейм, В.М. Марахонов, Р.П. Сейсян. Письма ЖТФ, 6 (17), 1034 (1980).

[3] Электронный ресурс АО „Научно-исследовательский институт полупроводниковых приборов“. https://www.niipp.ru/

[4] Электронный ресурс „EPISTAR corporation“. https://www.epistar.com/EpistarEn/prodInfo

[5] Peng Bai, Yueheng Zhang, Tianmeng Wang, Zhiwen Shi, Xueqi Bai, Chaoying Zhou, Yaning Xie, Lujie Du, Mengting $\mathrm{Pu}$, Zhanglong Fu, Juncheng Cao, Xuguang Guo, Wenzhong Shen. Semicond. Sci. Technol., 35(3), 035021 (2020). DOI: 10.1088/1361-6641/ab6dbf

[6] Su-Chang Ahn, Byung-Teak Lee, Won-Chan An, Dae-Kwang Kim, In-Kyu Jang, Jin-Su So, Hyung-Joo Lee. J. Korean Phys. Soc., 69 (1), 91 (2016).

[7] А.В. Малевская, Н.А. Калюжный, Д.А. Малевский, С.А. Минтаиров, Р.А. Салий, А.Н. Паньчак, П.В. Покровский, Н.С. Потапович, В.М. Андреев. ФТП, 55 (7), 614 (2021). DOI: 10.21883/FTP.2021.07.51028.9646

[8] E. Fred Shubert. Light-emitting diodes (second ed.), (Cambridge University Press, 2006).

[9] А.В. Малевская, Н.А. Калюжный, Д.А. Малевский, С.А. Минтаиров, А.М. Надточий, М.В. Нахимович, Ф.Ю. Солдатенков, М.3. Шварц, В.М. Андреев. ФТП, 55 (8), 699 (2021). DOI: 10.21883/FTP.2021.08.51143.9665

[10] В.М. Емельянов, Н.А. Калюжный, С.А. Минтаиров, М.В. Нахимович, Р.А. Салий, М.3. Шварц. ФТП, 54 (4), 400 (2020). DOI: 10.21883/FTP.2020.04.49148.9321

[11] K. Tai, L. Yang, Y.H. Wang, J.D. Wynn, A.Y. Cho. Appl. Phys. Lett., 56, 2496 (1990). DOI: 10.1063/1.10286

[12] F.A.I. Chaqmaqchee, S. Mazzucato, Y. Sun, N. Balkan, E. Tiras, M. Hugues, M. Hopkinson. Mater. Sci. Engin. B, 177, 739 (2012). DOI: 10.1016/j.mseb.2011.12

Редактор Г.А. Оганесян 


\section{High efficiency $(E Q E=37.5 \%)$ infrared $(850 \mathrm{~nm})$ light-emitting diodes with Bragg and mirror reflectors}

A.V. Malevskaya, N.A. Kalyuzhnyy, S.A. Mintairov,

R.A. Salii, D.A. Malevskii, M.V. Nakhimovich,

V.R. Larionov, P.V. Pokrovskii,

M.Z. Shvarts, V.M. Andreev

loffe Intitute,

194021 St. Petersburg, Russia

Abstract Developed and investigated are IR light-emitting $(850 \mathrm{~nm})$ diodes based on $\mathrm{AlGaAs} / \mathrm{Ga}(\mathrm{In}) \mathrm{As}$ heterostructures grown by the method of MOC-hydride epitaxy, with multiple quantum wells in active region, and a double optical reflector, consisted of multilayer $\mathrm{Al}_{0.9} \mathrm{Ga}_{0.1} \mathrm{As} / \mathrm{Al}_{0.1} \mathrm{Ga}_{0.9} \mathrm{As}$ Bragg heterostructure and argentum mirror layer. Light-emitting diodes with the external quantum efficiency $\mathrm{EQE}=37.5 \%$ at current densities more than $10 \mathrm{~A} / \mathrm{cm}^{2}$ have been fabricated. 